Sris 3

(1832-1850)

\title{
natom
}

\section{Mineralogical notices}

\section{Delesse}

To cite this article: M. Delesse (1845) IV. Mineralogical notices, Philosophical Magazine Series 3, 26:170, 36-37, DOI: 10.1080/14786444508645068

To link to this article: http://dx.doi.org/10.1080/14786444508645068

曲 Published online: 30 Apr 2009.

Submit your article to this journal 주다

Џll Article views: 2

Q View related articles $₫$ 
Transactions for 1821, with only one slight point of difference, viz. that Mr. Kemp neutralizes his solution cold, while Sir J. Herschel recommends the neutralization to be performed at a boiling temperature, a precaution which, as will appear on a perusal of the paper in question, is by no means to be neglected when a mathematically rigorous separation of the oxides is desired.

Mr. Kemp also notices that where cheapness is an object, carbonate of soda may be substituted for that of ammonia. Sir J. Herschel has shown that any earthy or metallic carbonate will equally answer the purpose, so that (for the preparation of the sulphate at least, for manufacturing purposes) chalk would be that substance to which the manufacturer would resort, as no harm can arise from adding it in any excess, and the small quantity of sulphate of lime remaining in solution would be readily separated by evaporation to dryness and redissolution. An experiment is related in the paper referred to, where a very minute per-centage of manganese was insulated from an enormous excess of iron by simply filtering the hot solution through chalk.

I am, Sir, \&c.,

AnNotator.

IV. Mineralogical Notices*.

Analysis of the Greenorite, by M. Delesse.

THIS mineral, found at Saint Marcel in Piedmont by

M. Bertrand de Lom, has been described by M. Dufrénoy, who has given its crystallographic characters; the analysis made by M. Cacarrié on a too small quantity presented much uncertainty, which has induced me to submit it to fresh investigation. I have in fact found that if the crystallization gave an exact idea of that species, its composition had caused it to be regarded, erroneously, as a titanate of manganese, whereas it is a silico-titanate of lime, analogous to sphene, as results from the following analyses:-

I. Oxygen. II. Oxygen.

Silica $\cdot \begin{array}{ccccccc}. & . & 29 \cdot 80 & 15 \cdot 48 & 30 * 40 & 15 \cdot 79 & 2\end{array}$

Oxide of titanium . . $43.00 \quad 17.07 \quad 42.00 \quad 16.68 \quad 2$

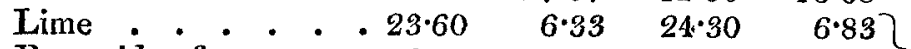

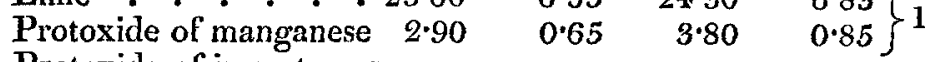

Protoxide of iron, traces.

$$
\overline{99 \cdot 30} \overline{100 \cdot 50}
$$

These elements are well enough represented by the formula

(2 $\left.\dddot{\mathrm{Si}} \dot{\mathrm{R}}^{3}+\ddot{\mathrm{T}} \mathrm{i}^{2} \dot{\mathrm{R}}\right)+3 \dddot{\mathrm{Si}} \ddot{\mathrm{T}} \mathrm{i}^{2}$.

* From the Comptes Rendus, November 11, 1844. 


\section{Analysis of the Bornine of Brazil (Telluret of Bismuth), by M. A. Damour.}

The bornine, the analysis of which I present, is in micaceous laminæ having the brilliancy of polished steel, slightly flexible, and very thin; heated on charcoal it fuses, becoming surrounded with a white ring and a green ring, and finally disappears in the pores of the charcoal.

In the open tube it fuses on the first application of heat, disengages a sulphurous smell, then white fumes of oxide of tellurium, and toward the close of the operation a marked smell of selenium. In the upper part of the tube a white crust is observed surmounted by a light brick-red layer, attributable to the condensation of the selenium. The lower part of the tube remains covered with a yellowish residue of oxide of bismuth.

Nitric acid dissolves it very easily with a disengagement of nitrous gas; analysed by this means the bornine of Brazil has given the following results :-

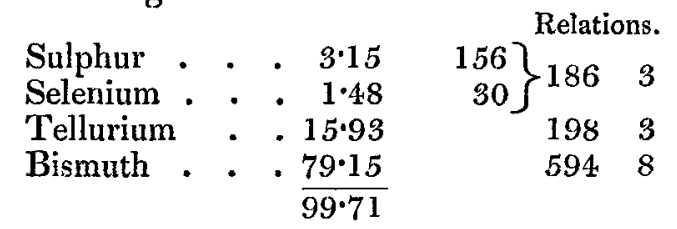

In taking the number $1330 \cdot 376$, adopted by MM. Regnault and Rose, as the atomic weight of bismuth, and that of $802 \cdot 131$ for the atomic weight of tellurium, the preceding results might be expressed by the formula

$$
\mathrm{Bi}^{2} \mathrm{~S}^{2}+3 \mathrm{Bi}^{2} \mathrm{Te} \text {. }
$$

This composition differs considerably from the results obtained by MM. Berzelius and Wehrle for the bornine of Chemnitz, as well as those which the bornine of DeutschPilsen yielded to the latter chemist.

These differences might perhaps lead us to adopt three species of bornine, but we rather think that, if tellurium and bismuth can combine in exact proportions, they may also combine in very variable quantities. To decide this delicate question-one too which occurs with many metallic minerals -it is necessary to wait until crystals of bornine combine the two characters which determine the formation of mineral species, namely the atomic composition and the crystalline form. 